\title{
The National Library of Argentina: exhibiting astronomy-related rare books
}

\author{
Alejandro Gangui ${ }^{1,2}$ \\ ${ }^{1}$ Instituto de Astronomía y Física del Espacio / CONICET, \\ Ciudad Universitaria, 1428 Buenos Aires, Argentina. \\ email: gangui@df.uba.ar \\ ${ }^{2}$ Centro de Formación e Investigación en la Enseñanza de las Ciencias, \\ FCEyN, Universidad de Buenos Aires, Argentina
}

\begin{abstract}
Astronomical and cosmological knowledge up to the dawn of modern science was profoundly embedded in myth, religion and superstition. Many of these inventions of the human mind remain today stored in different supports: medieval engravings, illuminated manuscripts, and of course also in old and rare books.
\end{abstract}

Keywords. Astronomy, history of science, public exhibition

\section{Introduction}

Old and rare books: vestiges of the past which are well preserved in special reserves of main libraries, and constitute a source of pride of these institutions.

Among the many incunabula owned by Argentina's National Library, a couple of volumes stand out. The Liber Chronicarum cum figuris et ymaginibus, compiled by the humanist Hartmann Schedel and printed by Anton Koberger in 1493 (the famous Nürnberg chronicle) is one of the "must see" of the Library. It includes not only a description of Pliny's marvelous hominids -headless Libyans endowed with eyes and mouth in their chests, Cyclopes from India and other mirabilia- but also many images with clear cosmological flavor.
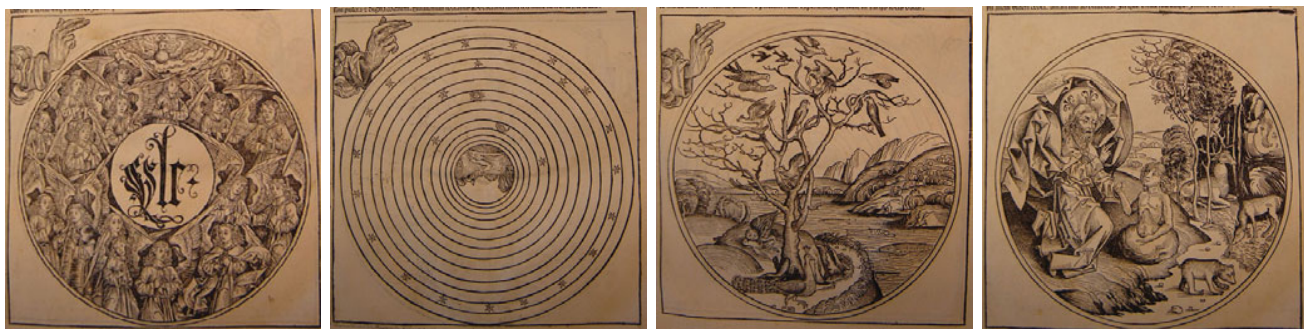

Figure 1. In principio... the Nürnberg chronicle, by Hartmann Schedel, 1493.

This original Latin edition includes, among its nearly 1800 engravings, and of most interest to us, a thorough description of the seven ages of the world after Creation, beginning with a biblical heptameron, of which already the forth day shows a nice geocentric Ptolemy's universe (second picture in Fig. 1).

The Library also owns a Venice 1484 copy of Dante's Divine Comedy, with comments by Cristoforo Landino, which beautifully illustrates Beatrice guiding the pilgrim across the astronomical and metaphysical spheres of the celestial Paradise.

These and dozens of other equally interesting books build up an important part of both literary and pre-scientific culture. However, only a handful of persons (mainly researchers) 


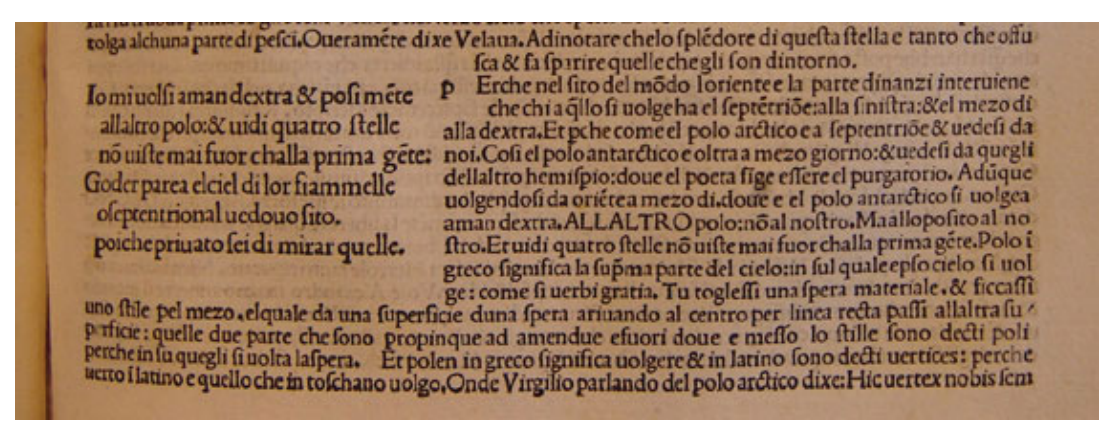

Figure 2. Dante's Divine Comedy (Venice, 1484) with comments by Cristoforo Landino. Upon the other pole, and saw four stars/ Ne'er seen before save by the primal people./ Rejoicing in their flamelets seemed the heaven./ O thou septentrional and widowed site,/ Because thou art deprived of seeing these! (Purgatorio I, 22-27, translation by H.W. Longfellow). "Quatro stelle...": is he making reference to the Southern Cross ? (Gangui 2008).

have access to them. Just as we all know that the feeling of seeing Mars in pictures cannot be compared to the experience of actually seeing it through a telescope, in the case of old books, the project of exhibiting them is much more rewarding than just looking at them through the internet. Partly because of this, we are organising an exhibition of rare books with astronomical flavor.

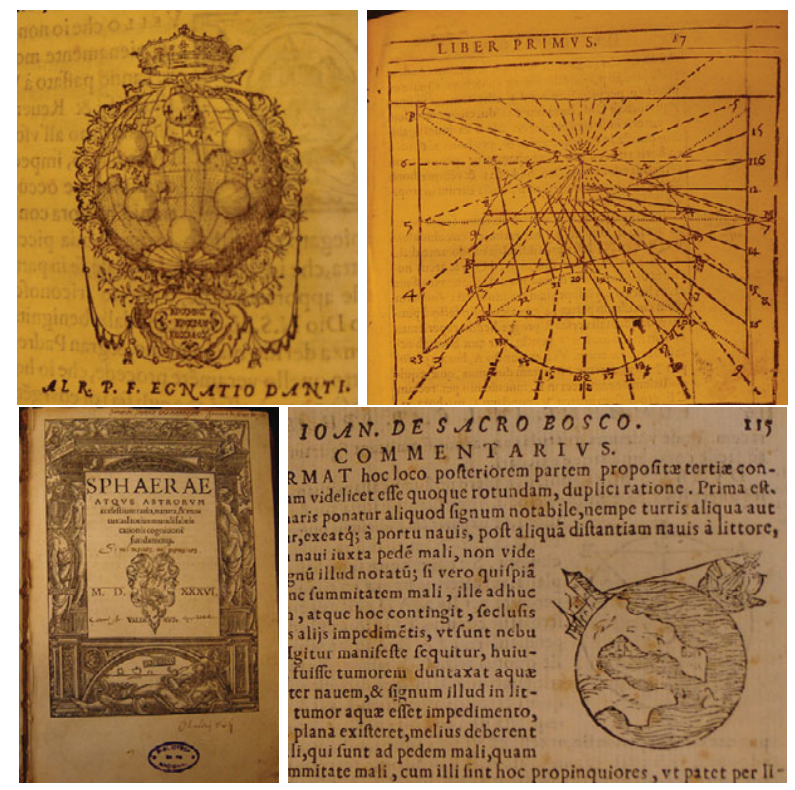

Figure 3. Egnatio Danti's Trattato dell'astrolabio (1569), Voello's De horologiis (1608), Iacobus Valderus' Sphæra (1536), Clavius' commentary of Sacrobosco'sSphæra (1585).

Many other old or rare books are also included in our list: Iacobus Valderus' Sphæra (1536), Egnatio Danti's Trattato dell'astrolabio (1569), Clavius' commentary of Sacrobosco's Sphæra (1585), Joanne Voello's De horologiis (1608), Henrico Hofmanno's De octantis (1612), Blaeu's Theatrum orbis terrarium (1640), and a long etcetera. Some of these books were presumably brought to the River Plate by the Catholic religious order of the Jesuits during the 18th century. Hence, these books allow us to reconstruct the kind of science imparted in our country at that time. Among these books, German Je- 
suit Athanasius Kircher's thick and numerous volumes, with their gorgeous engravings illustrating all possible areas of knowledge, naturally attract the attention: his Musurgia universalis (1654) depicts cosmic harmony as musical sounds emanating from an organ played by God; his Ars Magna Lucis et Umbrae (1671) shows the analogy between micro and macro cosmos, with man placed both at the center of the universe and of the zodiacal signs (Fig. 4).
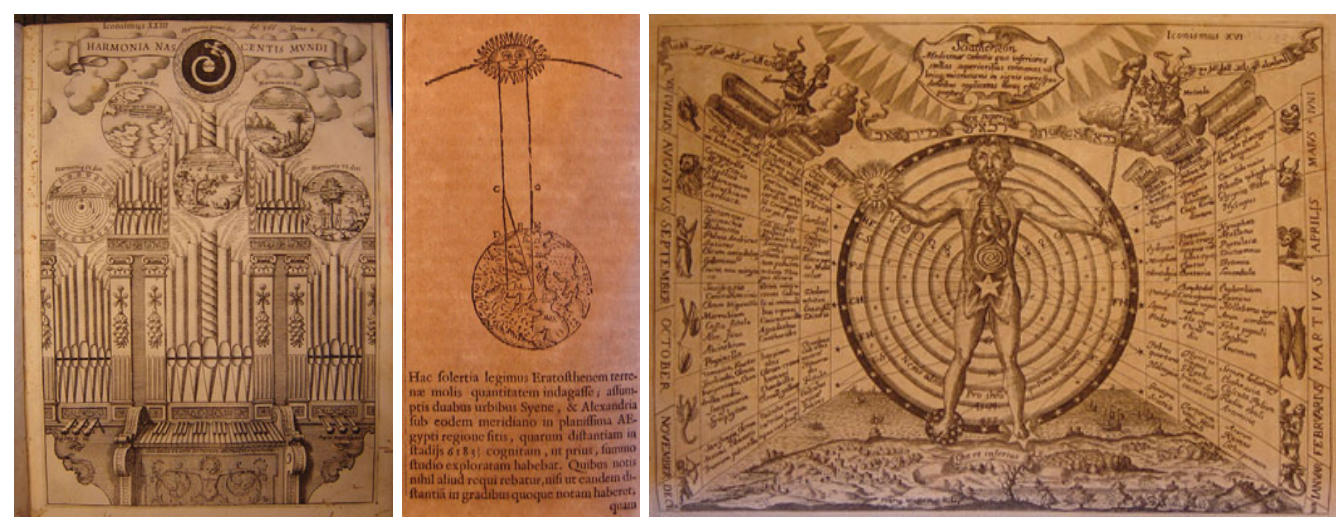

Figure 4. Athanasius Kircher's Musurgia universalis, 1654 (left) and a couple of images from Ars Magna Lucis et Umbrae, 1671 (depicting Eratosthenes' method to measure the circumference of the earth -image in the middle- and the micro and macro cosmos connection in a sort of Vitruvian man representation, on the right).

In Kircher's Mundus subterraneus (1678) the frontispiece shows a lady (the allegory of Astronomy) inspecting a celestial globe and taking notes with a plume d'oiseau, while another feminine character looks through a telescope. Inside the book we find a sketch of the Moon as an aqueous body, with spots, mountains and sources, as well as other rough earthy textures scattered on its visible face, and another of the Sun, divided in different regions, including an equatorial torrid zone, quite similar to the one of the Earth at the time, and covered with drawings of smoke and fires as sources of Sun spots.
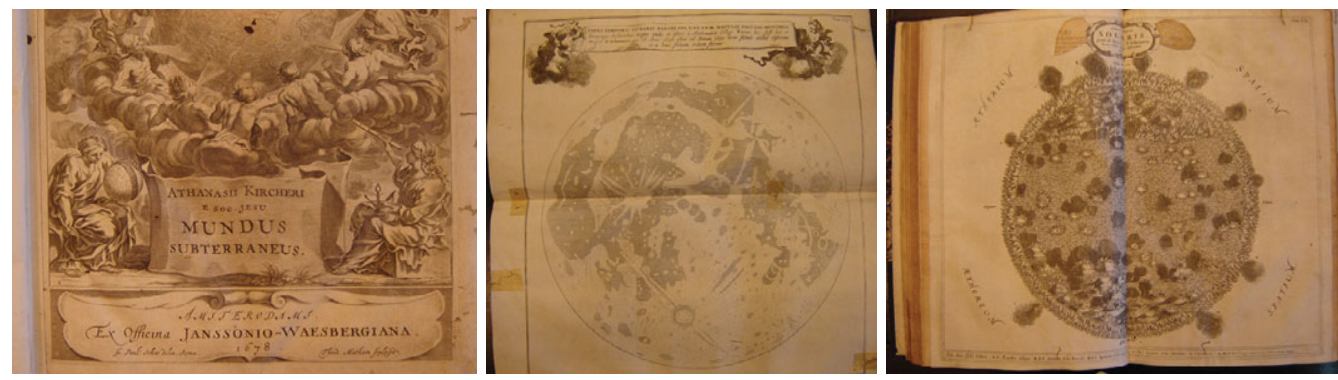

Figure 5. Kircher's Mundus subterraneus (1678). Frontispiece and two sketches: of the Moon (middle) and of the Sun (right).

Finally, father Gaspare Schotto's Iter exstaticum Kircherianum, of 1671, shows in its very frontispiece a peculiar engraving of Kircher himself (as Theodidactus, the disciple of God) when, guided by angel Cosmiel, he travels across the universe, in a clear parallel to Dante's voyage following his donna-angelo. The universe depicted is neither Ptolemaic nor Copernican, but that of Tycho Brahe, with the Sun orbiting the Earth, while the 

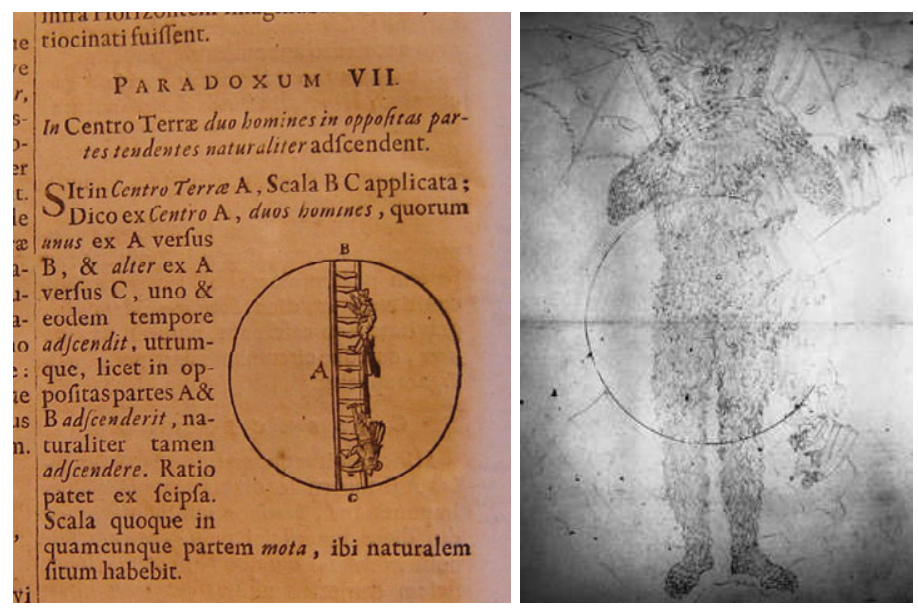

Figure 6. The image on the left is from Kircher's Mundus subterraneus and shows how two persons travelling from point A -located at the center of the Earth- have to go in opposite directions to reach the surface, "climbing upwards" with their stairs. A similar situation occurred to Dante in the last canto of the Inferno when, together with V irgilio, descended along the giant Lucifer's body, who was stuck in the center of the Earth and, suddenly, got turned upside down, as shown in this Sandro Botticelli's drawing for the Commedia (image on the right).

rest of the planets complete their movements around the Sun; a clear eclectic cosmology agreeing well with the author's world view.
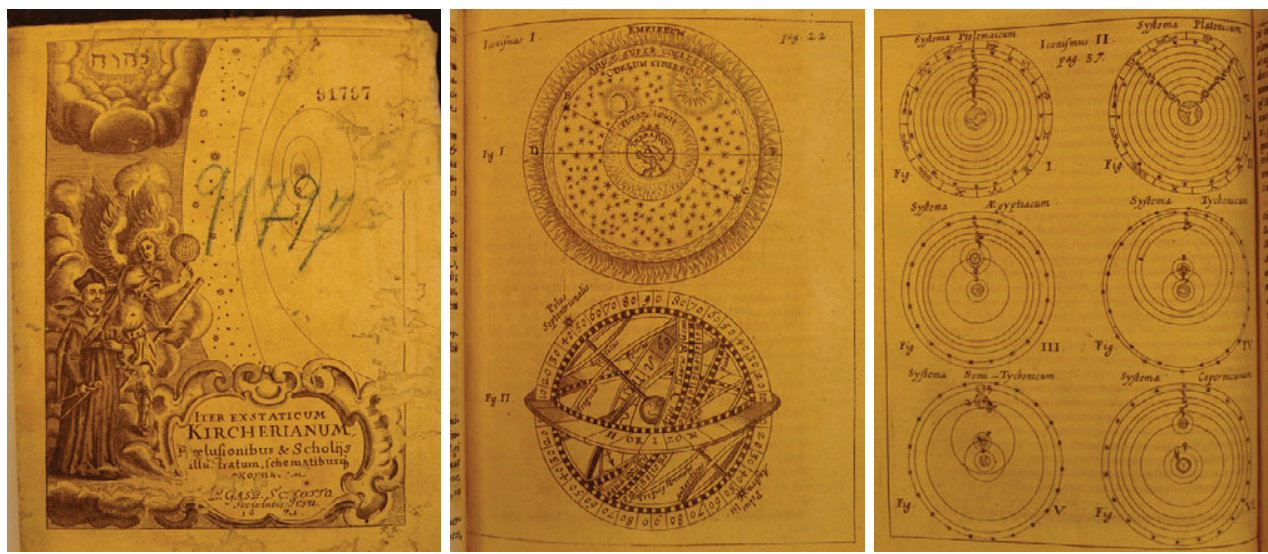

Figure 7. Gaspare Schotto's Iter exstaticum Kircherianum, 1671. Frontispiece depicting a Tychonic universe (left) and two of the most noteworthy pages: a representation of the elements surrounding the Earth, from the Empyrean downwards, and the different principal circles of the sky (middle), while the image on the right shows a collection of the most representative systems of the world, from the Ptolemaic to the Copernican models.

The planned exhibition will collect not only these and other books, but also historical documents, maps and drawings (may be also artifacts). Hopefully, it will offer a timeline of our understanding of old and renaissance astronomy and, with it, part of the imago mundi of the time.

\section{References}

Gangui, A. 2008, Poética Astronómica: El cosmos de Dante Alighieri (Buenos Aires: Fondo de Cultura Económica) 